\title{
Development Level of Engineering Students' Inductive Thinking
}

\author{
Péter Tóth, Kinga Horváth, Katalin Kéri
}

J. Selye University

Bratislavská cesta 3322, SK-94501 Komárno, Slovakia

e-mails: tothp@ujs.sk,horvathki@ujs.sk, kerik@ujs.sk

\begin{abstract}
In Hungary, the rate of drop-out in technical higher education, exceeds the average of the European Union. The affective, sociological and socio-economic factors hiding behind the reasons have already been examined by several researches, however, less attention has been paid to the students' cognitive deficiencies although inductive reasoning is of decisive importance in gaining knowledge e.g. in mathematics and natural sciences. Based on these findings, the object of this research, was on one hand to describe the development level of the inductive reasoning and thinking of students starting their studies in technical higher education, and on the other hand, to prove or disprove the correlation between the task solution time and the result achieved in the inductive test. The research implemented by means of an online test involved 253 students; of the components of inductive thinking, we examined the development level of abstract, analogue and diagrammatic thinking.
\end{abstract}

Keywords: drop-out; measuring competences; inductive thinking; engineering education

\section{Introduction}

One of the vital problems for Hungarian higher education, and within that technical higher education, is a high drop-out rate. The question arises as to how much advanced logical thinking is required, for the successful acquisition of real subjects, which can cause serious difficulties in technical higher education. It is hypothesized that underdeveloped logical thinking leads to drop-out due to the ineffective fulfillment of these subjects. Advanced inductive thinking is essential for learning mathematics and basic technical subjects. Knowing this, at the beginning of studies, it would be possible to differentiate the development of the students, to fill their gaps, and through these to reduce the drop-out rate.

The Hungarian data exceeds the EU members' $25-30 \%$ average drop-out rate by almost $10 \%$. According to the data of 2016 , the rate of those gaining a degree in the technical field was $41.6 \%$ (completion rate), the level of drop-out was $39.6 \%$ 
while the proportion of those not yet having completed their studies (e.g. because of the lack of a language exam) and having changed their training was $18.8 \%$. The numbers in the non-technical field show this picture: $53.5 \%, 33.6 \%$ and $13.0 \%$ [1] [2]. As regards to the completion rate, the picture seen varies by types of training. In technical higher education, $35.7 \%$ of full-time students dropped out, while in correspondence training this rate was $54.6 \%$, and the rate of those changing their trainings or having not yet graduated was 19.2 and $17.6 \%$. Regarding financing, the drop-out rate was $35.3 \%$ with state-funded students and $53.9 \%$ with fee-paying students. [2]

In students' registries, the following reasons of drop-out are enlisted in most cases:

(1) Attributable to deficiencies in the studies:

(a) the number of retake or repeat exams has reached the maximum

(b) the number of passivated semesters has reached the maximum

(c) non-completion of training requirements

(2) Financial problems: e.g. non-payment of the training fee

(3) Financial problems originating in study insufficiencies: reclassification from state-financed to fee-paying status

(4) Unknown reasons: e.g. voluntary interruption of studies. [2]

Searching for the real reasons of drop-out, several empiric researches have been implemented during the latest 40 years. [1] [3] [4] Analyzing these, the following categories can be distinguished:

(1) Cognitive deficits (existing knowledge, competences, skills and capabilities)

(2) Affective deficits (commitment for the chosen course, interest, motivation, scale of values, career prospects, prestige and stress tolerance)

(3) Social reasons (financial problems, living, student work, residence, lack of morally supporting environment or disadvantageous socio-economic status)

(4) Reasons originating in the insufficient selective functions of the educational system (e.g. entrance exam)

(5) Reasons originating in the insufficient operation of the institution (deficiencies in learning support, insufficient level of student services, qualitative deficiencies of teaching or deficits in the equipment)

By the early 2010s, drop-out became an acute problem in Hungarian higher education, as well. Several of the papers published during the latest 10 years [2] 
[5] [6] [7] have revealed the affective, sociological and socio-economic reasons of drop-out. When categorizing the reasons, they described:

(1) Institutional ones (reputation of the institution, infrastructure supporting learning, committed lecturers, student-friendly nature of study classes, etc.)

(2) Social and cultural ones (social status, socio-economic status, decreasing impact of degree in the student's micro environment, etc.)

(3) Economic ones ("it is more worth working than staying at the university" working in parallel, training fee, etc.)

(4) Personal, pedagogical, psychological and learning-related ones

In terms of drop-out, the lack of ICT competences [25] and the inadequate organization of the learning process [26], inadequate level of comprehension [27], and lack of self-confidence [28] should be highlighted.

In the research implemented in Hungary, less attention has been paid to the students' cognitive deficiencies albeit this is the one lecturers meet in most cases during teaching their subjects. This is exactly why the Ministry for Innovation and Technology, which is responsible for the development of higher education, set a target to introduce competence measurement in higher education. However, the question of what competences connectible to learning difficulties should be measured arises.

As in natural scientific, and so in engineering training, mathematical and natural scientific cognition is of decisive importance, we selected certain components of inductive thinking and reasoning as the focus of our competence measurement.

There is a further aspect that enhances the relevance of the research. A strong demand is being formed on behalf of the labor market that can be best expressed by the term soft skills (labor market key competencies). Several studies point to the fact that career starter employees arrive from higher education to the labor market unprepared especially in terms of these competences [6], and it is not rare that companies consider these skills more important than professional preparedness [7], or call the trainers to develop these competences, as well [8]. According to the Manpower Group, $16 \%$ of the jobs in Europe remained unfilled for reason of soft skill deficiencies.

Opinions strongly differ concerning the question of what competences belong to soft skills. Mainly intra- and inter-personal cognitive competences and attitudes are mentioned. One of these is the higher-grade cognition, the components of which are problem solving and critical thinking as well as judgement and decision making ability. In the world of labor, they appear as a demand in their organic relation system [9] [10] [11] [12]. 
Therefore, in some sense, our research can be considered a "situation survey" since our interest was focused at the development level of the students entering higher education in terms of logical thinking, which is one of the labor market key competences, i.e. what is the initial level of their skills in this field.

\section{Inductive and Abstract Reasoning and Thinking}

When identifying the various aspects of reasoning and thinking, we use plenty of attributives. Possible forms include but are not limited to formal, informal, everyday, logical, deductive, inductive, abstract, analytical, verbal and quantitative while with regards to cognition, the list includes, inter alia, higher rank, critical, creative, problem solving, rational, lateral, inductive and deductive. On the following pages we will discuss the important field of Inductive reasoning and cognition.

Inductive cognition can be explained as the recognition of regularities and irregularities in a process during which we identify similarities, differences as well as similarities and differences by comparing attributes and relations in the tasks containing verbal, pictorial, geometrical and numerical figures. [13] Thus, induction can be related to characteristics and relations. Similarities in characteristics result in generalization, while differences result in discrimination and the common result of the two will be classification. By way of similarity of the relations, relationships will be recognized, while their differences lead to the differentiation of relationships, and the common result of the two will be system construction. Analogue can be considered one of the most important problem groups of induction and it has components like cause and reason or associationbased whole and parts relations. [14]

Abstract thinking is a significant form of human knowledge. It allows us extract the essence of complicated and abstract things and to recognize interrelations. And this is of basic importance in gaining knowledge. Human differs from other living beings also in having the capacity to explain and get to know the surrounding world in a way transcending sensation and perception. For example, an engineer is able to describe the rules determining certain technical phenomena by abstraction, is able to create an abstract system by applying them, and is also able to think within this system. Technical modelling is a good example of this.

Understanding, reconstructing and creating technical models requires developed abstract cognition of the students, which in most cases means a problem for the students in learning mathematics and natural scientific (including technical scientific), i.e. STEM subjects. Thus it is not by chance that drop-out shows the highest level in relation to these subjects. 


\section{Objective and Means of the Research}

As presented above, inductive cognition plays an important role in understanding the learning content and in performing well on the labor market. Therefore, the double demand of reducing drop-out and offering better preparation for the labor market makes our research really timely.

The speed of cognition reflects the time the experimental person needs to solve a certain test item. Carroll presumes that there is some relationship between the competence level and the speed of cognition and declares that in general, the person with developed cognitive skills solves a mathematical problem faster than the one with weaker capacities. [16] Some query this statement. [17] According to Sternberg and Pellegrino, the time used for finding a good answer can predict performance more precisely than the skill level itself. [15]

Based on the above, the research aimed to:

(1) Describe the development level of the inductive thinking of the firstgrade students starting their studies in technical higher education

(2) Prove or disprove the relationship between the time used for task solution and the performance achieved in the inductive test.

A question arises here: how can the development level of the students' inductive reasoning and reasoning be reliably measured without specific subject knowledge and skills (e.g. in mathematics or physics)? Several methods can be used ranging from certain intelligence tests (e.g. Raven) and inductive reasoning tests to special measurement tools focusing at the given skill component.

In this research we used the measurement tools developed by Psychometric Success WikiJob Ltd. (UK, London) who pay special attention to labor market demands. [18] When developing the test, the experts based their measurement tools on one- and multifactor intelligence tests. [15] The sample tasks of the test are available here: https://psychometric-success.com/

To examine cognition based on inductive thinking the developer elaborated the abilities presented in Figure 1. 


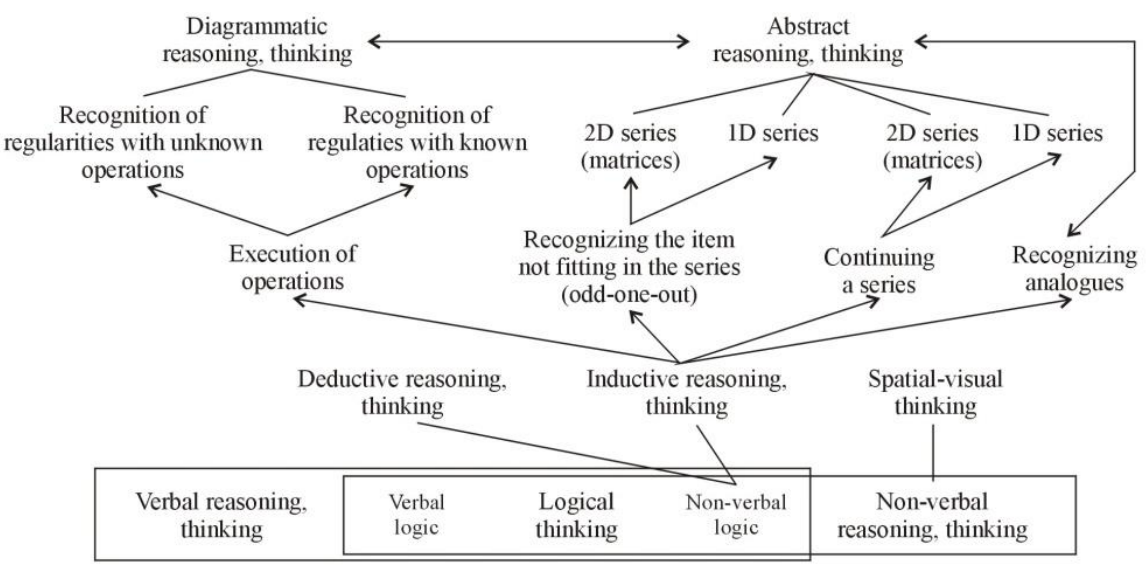

Figure 1

Task system examining inductive cognition

The problem for the respondent lies in the difficulty to recognize the logical relationships hiding behind the patterns included in the tasks (https://psychometric-success.com/). Problems root in the hardness of recognizing the change or repetition of these characteristics: (1) shape, (2) size, (3) color and (4) pattern. The tasks consist of visual patterns and geometrical figures and three types of problems must be solved by recognizing the logical relationships hiding behind them.

The following are the types of tests applied in this research.

- One-dimension series (Task1, Task2) require the ability to recognize relationships that are in many cases not obvious at the first glance. The recognition of the connections between the geometrical figures can be separated from the identification of the certain figures. The latter one must be clear for each of the experimenters. While solving a task, each characteristic of the geometrical figures must be identified and their correlations understood simultaneously. [19] Solving this type of problems requires such high level logical skills that promote the recognition of complex situations and thinking about them. In most cases, these processes are non-verbal and highly depend on sudden recognition and understanding. These are so fast that they do not have the time to get assimilated into the language. [20]

Several researches examined whether it was possible to conclude difficulty and performance from the time used for solution by items. According to Jacobs and Vanderventer, the difficulty level of the items is in connection with the number of the characteristics that must be compared and kept in mind simultaneously [19], so those achieving better results are able to keep several items in mind in parallel, however it can also mean that they laid 
more effort in the given item. [21] Vodegel Matzen et al. refer to Home and Habon's work according to which it is not possible to draw conclusions in terms of the difficulty level of the items from time consumption. [22]

Regarding one-dimension series, two types of exercises were included in the test: Task1: continuing a series, Task2: recognizing the item not fitting in the series (odd-one-out).

- With regards to recognizing analogues (Task3), already Sternberg pointed it out that the difficulty of the problems hides in recognizing the regularities rooting in the changes of the characteristics of the certain objects (A, B, C, X); to recognize these, the relation(s) (R) between the objects must be realized in terms of $\mathrm{A}$ and $\mathrm{B}$ and be applied in terms of $\mathrm{C}$ and $\mathrm{X}[23]$ :

$\mathrm{A}-\mathrm{R}-\mathrm{B}:: \mathrm{C}-\mathrm{R}-\mathrm{X}$

The experimental person may realize two strategies when selecting object $X:$ (1) sequential search, or (2) alternative search.

- The diagrammatic reasoning test measures the skill of how logically the person is able to follow the arranged sign series. Although the test consists of simple flow charts, its solution requires the experimenter to be able to track the changes taking place in the shape, color and size of the objects. This ability is outstandingly important, i.e. when analyzing certain system processes, in error correction and in system planning [24].

Diagrammatic reasoning was examined by means of two types of exercises in the test: Task4: recognition of regularities with unknown operations, Task5: recognition of regularities with known operations.

The online test, which was applied during the research implemented in 2019 at the Alba Regia Technical Faculty and the Rejtö Sándor Faculty of Light Industry and Environmental Engineering of Óbuda University, consisted of 6 items by task types, and allowed the measurement of the time used for the solution of the certain items. The latter one was of great important because of the second objective of this research.

\section{Research Participants}

The research involved 253 first-grade students, 171 men and 82 women; this rate conforms to the rate of the students at the two examined faculties. $79.05 \%$ of the students (200 persons) were less than 21 years old and $19.76 \%$ of them (50 persons) were between 21 and 25, which means that they had their secondary school leaving exam earlier, while 3 people $(1.19 \%)$ were older than 25 . 
$54.5 \%$ of the students (138 persons) continued their studies immediately after they had completed their secondary school studies, $26.1 \%$ (66 people) took their school leaving exams one year earlier, $10.7 \%$ (27 persons) did them $2,5.5 \%$ (14 people) completed them 3 years earlier and $3.2 \%$ (8 persons) had finished their secondary studies more than 3 years before entering university. $51.7 \%$ of the students (131 persons) took their secondary school leaving exams at secondary grammar schools, $23.7 \%$ (60 people) took them at secondary technical schools and $23.7 \%$ (60 people) attended vocational education after having completed their secondary studies. Regarding those having studied at secondary grammar schools, 100 persons $(39.5 \%)$ studied at 4 -5-grade schools, while 31 people $(12.2 \%)$ studied at $6-8^{\text {th }}$ grade talent development schools.

In engineering training, mathematics and natural scientific subjects, and because of text understanding, Hungarian language and literature are of outstanding importance, thus we asked the students about their school leaving exams results, as well. Almost one third of the students achieved the excellent grade in Hungarian and/or mathematics. By way of cross table analysis, we explored that only $12.3 \%$ of the students (31 persons) had achieved an excellent result in both subjects and 59.29\% (150 people) achieved a good or excellent result.

Regarding the students' higher education studies, $15.4 \%$ of them (39 persons) are involved in land surveying and land management engineering training, 11.5\% (29 persons) study mechanical engineering, 23.7\% (60 persons) attend industrial design engineering, 4.7\% (12 students) are at light industrial engineering, 9.9\% (25 persons) at environmental engineering, $7.5 \%$ (19 people) at electrical engineering and $27.3 \%$ (69 persons) at information technology engineering BSc.

We also examined the secondary school results by programs. In general, most of the students achieved 60-79\% results (mark 4) both in mathematics and Hungarian at most programs. However, the rate of those having achieved the best results (80$100 \%)$ is high amongst the students of the industrial design engineering (36.7\%) and the mechanical engineering (41.4\%) programs, and as for the land surveying and land management programs, the rate of those with medium results (40-59\%) was also high (46.2\%). Regarding the exam results in Hungarian language and literature, the picture is even more splendid. It is only the land surveying and land management program where the results are a bit weaker, $30.8 \%$ of the students gained grade $3(40-59 \%)$, at the same time, at the industrial design engineering program, $50.0 \%$ of the students and $30.8 \%$ at the environmental engineering specialization gained grade $5(80-100 \%)$ in this subject. 


\section{Results}

\subsection{Development Level of Inductive Reasoning}

The statistical indicators of the whole sample are summarized in Table 1. The best results were achieved in the analogue recognition task (Task3), while the weakest ones in the recognition of regularities including known operations (Task5). Probably, as for the latter one, the difficulty hid in the considerable memory burden as the results of the certain operations had to be stored in the short-term memory to modify them again by new operations and select the proper final result from the given list. These sensual - perceptional shifts may have caused difficulties to the students.

We compared the students' results by the various sub-samples, as well.

As for the sexes, men achieved significantly better results in continuing series (Task1: Mann-Whitney $\mathrm{U}=5622.500 ; \mathrm{p}<0.05$ ) and in recognizing regularities containing known operations (Tas5: Mann-Whitney $U=4987.000 ; p<0.05$ ), i.e. in the tasks where the average results were the lowest for the whole sample.

Table 1

Descriptive statistical indicators of the whole sample by tasks

\begin{tabular}{|c|c|c|c|c|c|c|c|}
\hline \multicolumn{3}{|c|}{$\begin{array}{l}\text { Descriptive statistical } \\
\text { indicators }\end{array}$} & Task1 & Task2 & Task3 & Task4 & Task5 \\
\hline \multirow{8}{*}{ 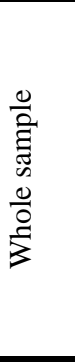 } & \multicolumn{2}{|c|}{$\mathrm{N}$} & 253 & 253 & 251 & 244 & 228 \\
\hline & \multicolumn{2}{|c|}{ M } & 3.64 & 4.14 & 4.75 & 4.09 & 2.54 \\
\hline & \multicolumn{2}{|c|}{ SD } & 1.270 & 1.363 & 1.329 & 1.887 & 1.664 \\
\hline & \multirow{2}{*}{$\begin{array}{c}95 \% \\
\text { Conf. int. }\end{array}$} & Low. & 3.48 & 3.97 & 4.58 & 3.86 & 2.32 \\
\hline & & Up. & 3.79 & 4.31 & 4.91 & 4.33 & 2.75 \\
\hline & \multirow[t]{3}{*}{$\%$} & $25 \%$ & 3 & 3 & 4 & 2 & 1 \\
\hline & & $50 \%$ & 4 & 4 & 5 & 5 & 2 \\
\hline & & $75 \%$ & 5 & 5 & 6 & 6 & 4 \\
\hline \multirow{4}{*}{$\stackrel{凶}{凶}$} & \multirow{2}{*}{$\begin{array}{c}\text { male } \\
(171 \text { p.) }\end{array}$} & $\mathrm{M}$ & 3,78 & 4.06 & 4.78 & 4.04 & 2.70 \\
\hline & & SD & 1.240 & 1.388 & 1.360 & 1.895 & 1.704 \\
\hline & \multirow{2}{*}{$\begin{array}{l}\text { female } \\
(82 \mathrm{p} .)\end{array}$} & $M$ & 3.34 & 4.30 & 4.67 & 4.21 & 2.23 \\
\hline & & SD & 1.288 & 1.302 & 1.267 & 1.876 & 1.551 \\
\hline \multirow{6}{*}{ 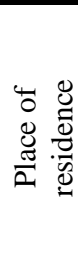 } & \multirow{2}{*}{$\begin{array}{l}\text { parents } \\
(136 \text { p. }) \\
\end{array}$} & $\mathrm{M}$ & 3.89 & 4.21 & 4.94 & 4.47 & 2.80 \\
\hline & & SD & 1.120 & 1.367 & 1.187 & 1.697 & 1.656 \\
\hline & \multirow{2}{*}{$\begin{array}{l}\text { sublet } \\
(23 \mathrm{p} .)\end{array}$} & $\mathrm{M}$ & 3.61 & 4.43 & 4.87 & 4.35 & 2.39 \\
\hline & & SD & 1.340 & 1.080 & 1.180 & 1.555 & 1.469 \\
\hline & \multirow{2}{*}{$\begin{array}{l}\text { hostel } \\
\text { (77 p.) }\end{array}$} & $\mathrm{M}$ & 3.32 & 3.97 & 4.51 & 3.46 & 2.15 \\
\hline & & SD & 1.352 & 1.460 & 1.466 & 2.088 & 1.623 \\
\hline
\end{tabular}


We also found significant differences in terms of the series continuation task (Task 1: $\left.\chi^{2}=9.820 ; \mathrm{p}<0.05\right)$ and the two tasks requiring the recognition of regularities (Task4: $\chi^{2}=11.856 ; p<0.05$ and Task5: $\left.\chi^{2}=6.993 ; \mathrm{p}<0.05\right)$ according to the students' place of residence (with parents, in sublet or hostel). The two examined faculties are situated in big cities (Budapest and Székesfehérvár) where the rate of those living in hostels is near to $30-30 \%$; in Budapest, almost $40 \%$ of the students live with their parents, while this number exceeds $60 \%$ in Székesfehérvár. The proportion of those living in sublets approaches $20 \%$ in Budapest, which can be reasoned by the low number of hostel rooms. $75.4 \%$ of the boarders but only $55.9 \%$ of those staying with their parents live in villages or small towns, and it is probably the impact of the countryside secondary schools with differing capabilities that is reflected in the students' results: the students staying with their parents were more successful in solving the more difficult tasks.

In terms of the secondary school leaving exams in mathematics, we found significant differences in the average results in the certain tasks $(p<0.05)$. The better result the person achieved during his/her mathematics exam, the better result could be expected in the tasks of the inductive test (Figure 2).

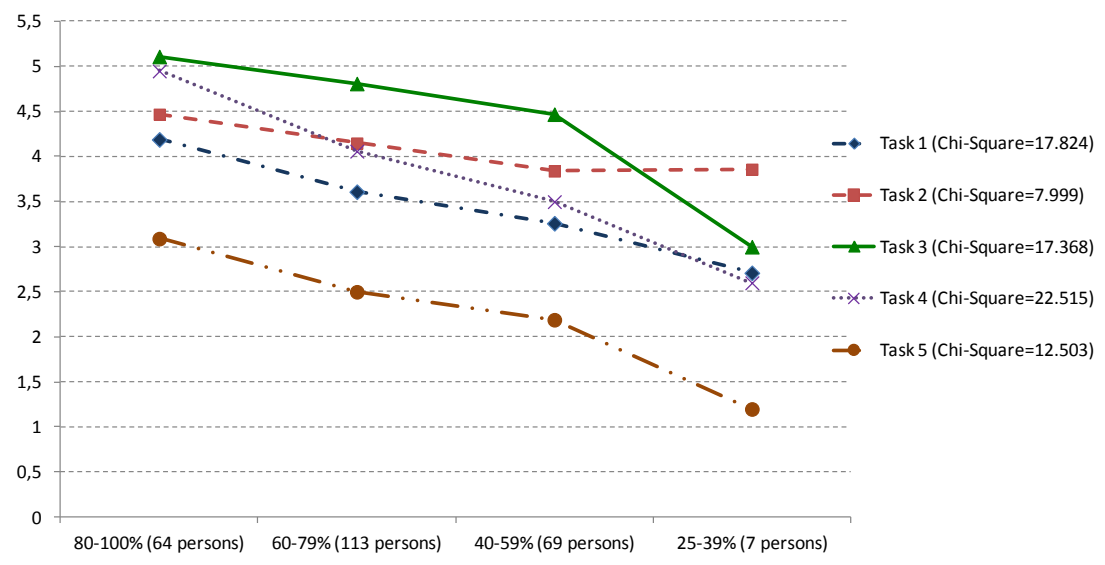

Figure 2

Average results by tasks in terms of the results of the school leaving exam in mathematics 


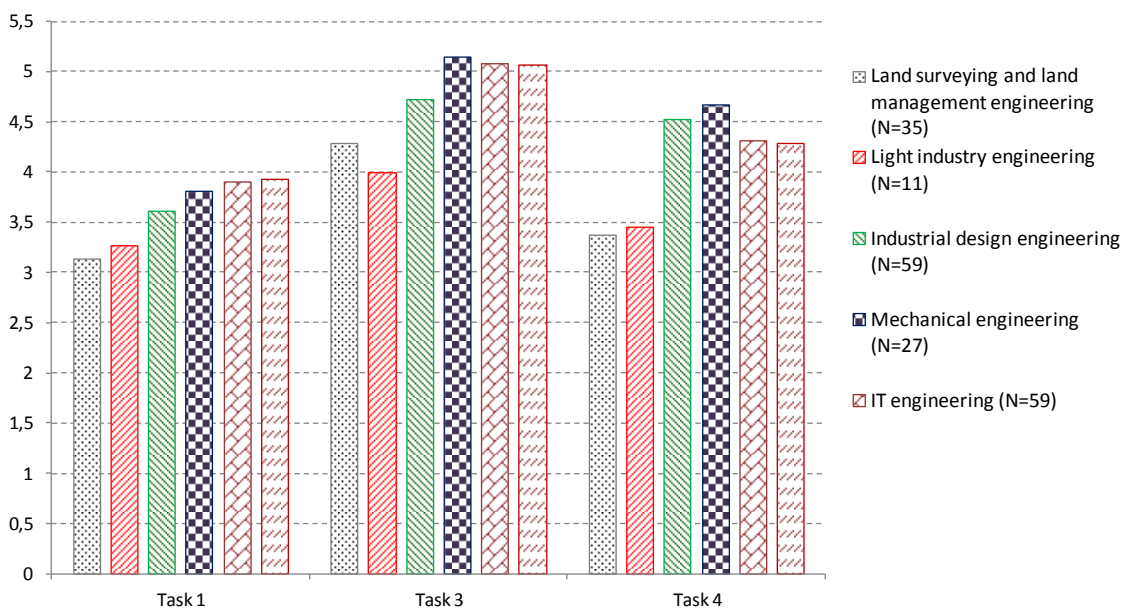

Figure 3

Average task results in terms of programs

Regarding the parents' educational level and the type of secondary school (secondary grammar or technical), we did not find significant differences in the averages of the certain types of tasks.

Figure 3 presents the average results of the certain tasks by programs. Concerning the tasks of continuing a series (Task1: $\chi^{2}=15.044 ; \mathrm{p}=0.010$ ), the analogue (Task3: $\chi^{2}=15.706 ; \mathrm{p}=0.008$ ) and the recognition of regularities containing unknown operations (Task4: $\chi^{2}=14.583 ; \mathrm{p}=0.012$ ), we found significant differences by programs. The best results were achieved by the students involved in mechanical engineering, information technology engineering and electrical engineering.

\subsection{Time Consumption on Task Solution}

The students were given 1800 seconds to solve the tasks. Online measuring allowed us to register the time spent on task solution by items, thus it became possible to analyze and compare them with the achieved results. 


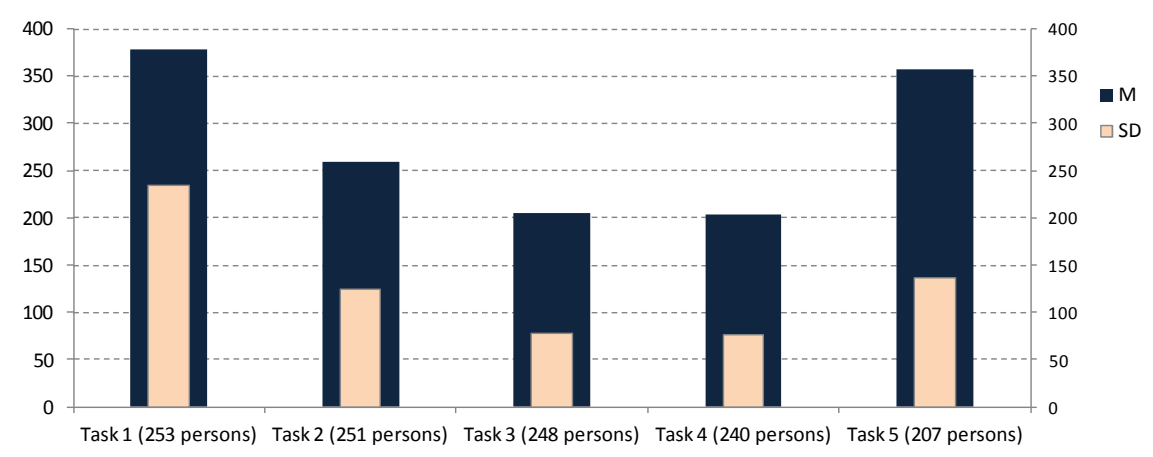

Figure 4

Mean and standard deviation of the time used to solve the given task types

The students consumed the most time for solving the series continuation (Task1) and the diagrammatic task containing known operations (Task5), and used the least time for the recognition of the analogue (Task3) and the diagrammatic items containing unknown operations (Task4) (Figure 4). If we compare these to the data presented in Table 1, reciprocal proportion-like relations will appear between the average results of certain task types and time consumption. However, high standard deviation rates imply considerable personal differences. We considered it important to analyze these and compare them to the achieved results. In case we concentrate at the first and the last type of tasks and analyze time consumption by items, as well, we will find a rather diverse phenomenon. The items of the series continuation task (Task1) differed in difficulty. It was easy for the students to understand what the task was, and time consumption clearly reflects the difficulty level of the item (Figure 5). It can also be clearly seen that the more difficult an item appeared to be, the bigger personal differences can be observed, which is proved by the high standard deviation levels.

Another phenomenon noticed, regarding the diagrammatic items using known operations (Task5) (Figure 6). According to Figure 4, is that the average time consumption of this task type almost agrees with that of the series continuation task (Task1). However, it can be clearly seen that the first item meant a real challenge for the students, i.e. at first they had faced problems of understanding. Later this decreased gradually. Personal differences were less typical here, which is reflected by much more regular standard deviation values, thus in this case, it was difficult to solve the items for everyone. 


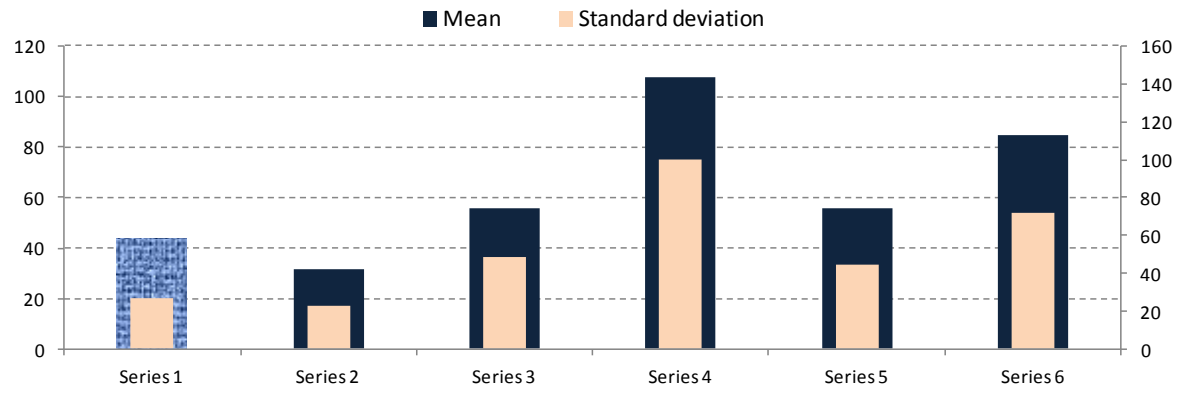

Figure 5

Mean and standard deviation of the time used to solve series continuation items

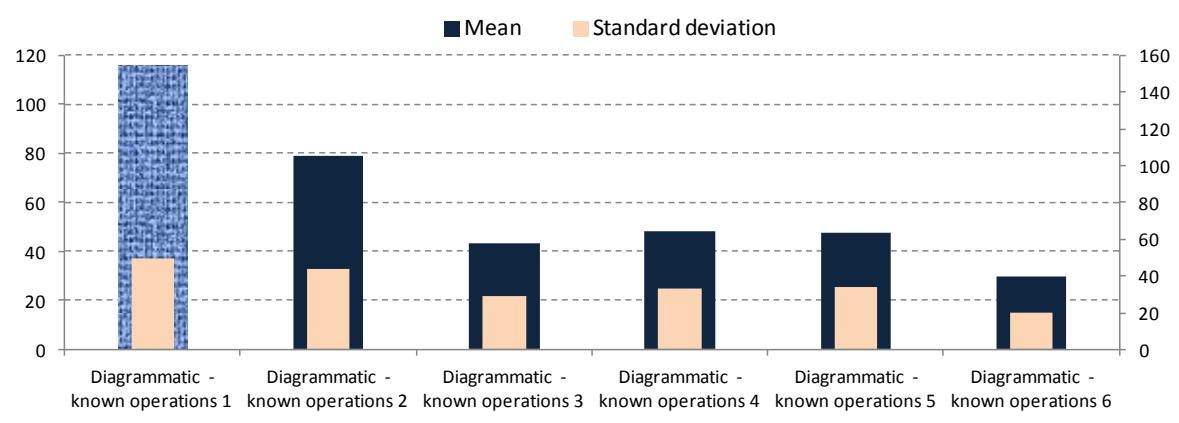

Figure 6

Mean and standard deviation of the time spent on solving the diagrammatic items containing known operations

Time consumption of Task 2 and Task 3 by items showed a picture similar to Figure 5 while that of Task4 was like Figure 6.

Regarding background variables, we found significant differences only in terms of the programs (Task1: $\chi^{2}=30.168 ; \mathrm{p}<0.05 ;$ Task2: $\chi^{2}=21.828 ; \mathrm{p}<0.05 ;$ Task3: $\chi^{2}=13.172 ; \mathrm{p}<0.05$; Task4: $\chi^{2}=14.284 ; \mathrm{p}<0.05$; Task5: $\left.\chi^{2}=11.975 ; \mathrm{p}<0.05\right)$. In line with the average results, it was the mechanical engineer and IT engineering students who spent the most time on solving the tasks (Figure 7). Behind the better average results by programs we find higher average time consumption.

According to Table 1 and Figure 4 it is clear that the diagrammatic task containing known operations (Task5) caused serious difficulties for the students, therefore, we have analyzed its items more deeply. Online measuring allowed the simultaneous storage of the students' solutions and time consumption as well as their analysis. Concerning item 1 (proper answer: A), whichever answer the student selected (the number of proper answers was very low), the time spent on solution was equally high, and was the highest for one of the bad solutions (E) (Figure 8, upper graph). 


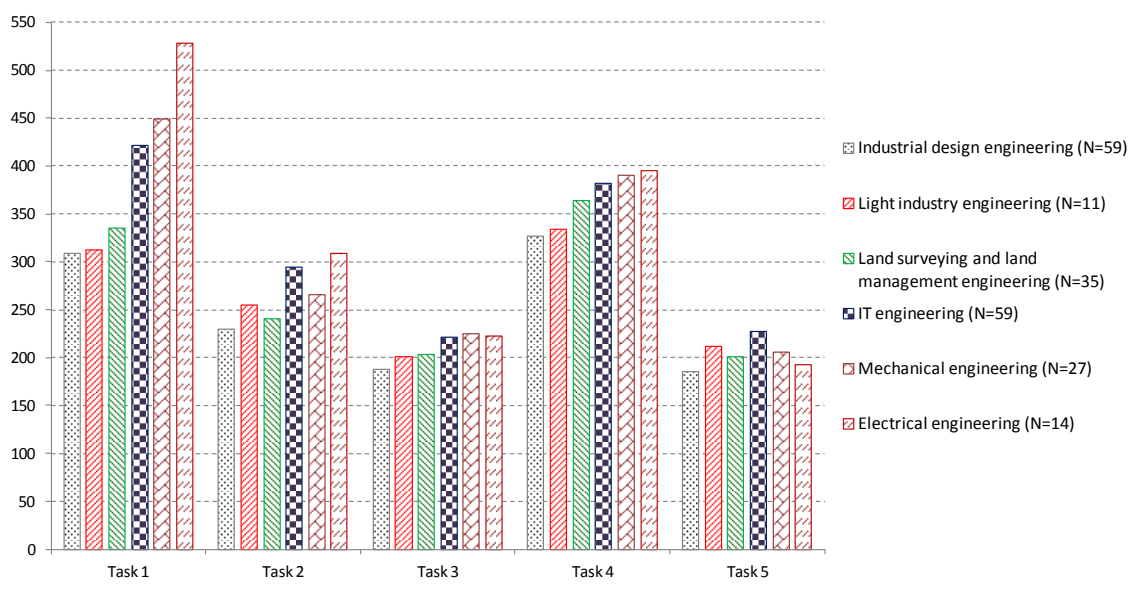

Figure 7

Average time used for task types by programs

However, as for items 5 and 6, the students chose the good answers at a higher rate although time consumption was much lower than it was at item 1 , however, time used for the good solutions was the highest (Figure 8, middle graph). Based on the standard deviation analysis (Figure 8, lower graph) we can state that concerning the three items, it is the time consumption of the students having selected the good solutions where the difference is the lowest, so they came to the good solution within almost the same time. Higher time consumption and standard deviation values of item 1 and the higher number of bad solutions can be reasoned, in addition to its difficulty, by its highly novel nature.

Next, we will analyze the results of the students having achieved the highest total scores as compared to the whole sample (10\% top), i.e. who are expected to have the most developed level of inductive cognition. In this case, students having collected 25 points or more are included in this category, altogether 32 persons. These students' scores (filled rectangles) and time consumption (empty rectangles) are presented in Figure 9, in terms of time consumption, in a growing order from left to right. Regarding the first five students, it is well visible that the students achieved high scores with relatively low time consumption. These respondents achieved 25-27 points within less than 18 minutes (quick-witted ones). The next category is made of 18 students who achieved similar results within less than 23 minutes (considered clever ones). The rest of the students used the available time almost fully (28-30 minutes) and reached good results (slow clever ones). 

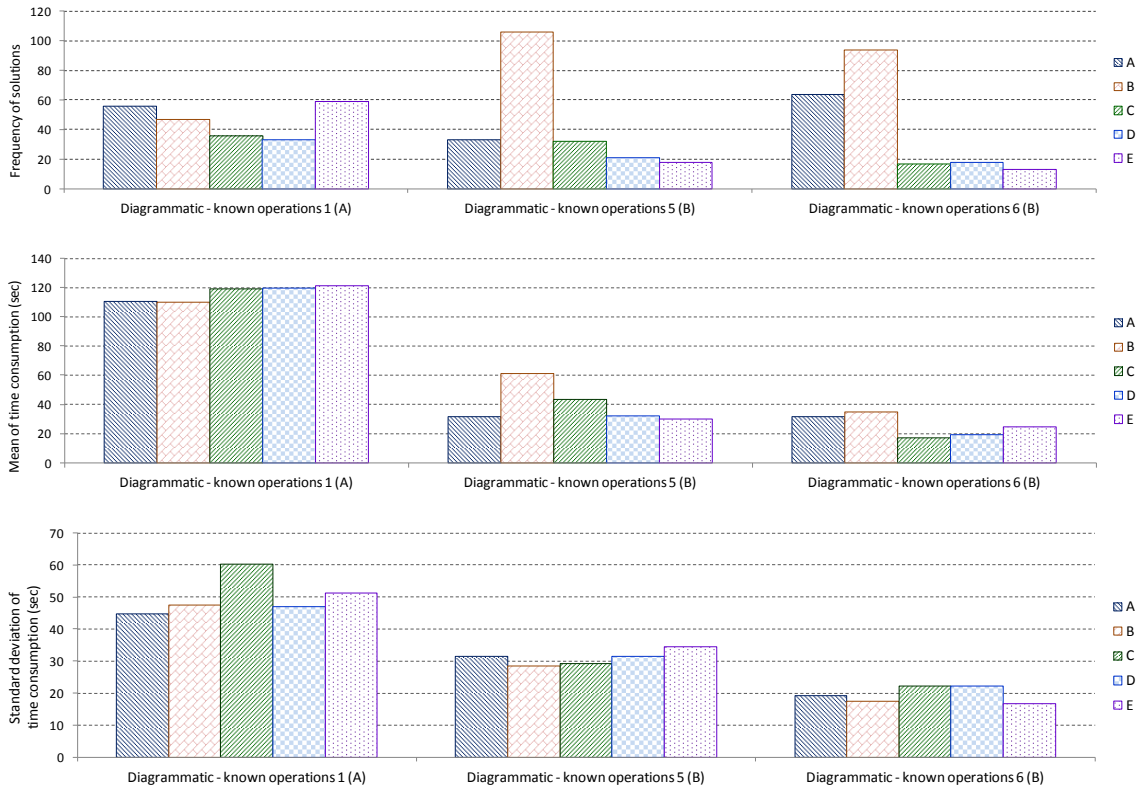

Figure 8

Solutions and time consumption of diagrammatic items (known operations)

To examine the relation between time consumption and inductive reasoning, the concept of specific performance was introduced by means of which the performance of the students with the best results was compared. In the inductive test, a specific performance was understood as the time necessary to achieve a unit of score, which was defined as the ratio of consumed time and the score achieved by items:

\section{Time consumption $_{x} /$ Score $_{x}$}

where time consumption ${ }_{\mathrm{x}}$ indicated the time spent on solving task $\mathrm{x}$ (6 items) by seconds, while score ${ }_{\mathrm{x}}$ represented the score reached during this time.

The students with the highest scores were ranked based on specific performance (Figure 9). $250 \mathrm{sec} /$ point as high specific performance was considered, which means that the students achieved a high number of points using little time. The values between 250 and $300 \mathrm{sec} /$ point were assessed as specific performance of medium level, while the values above were considered low specific performance, i.e. a high amount of time was used to reach one unit of points. Specific performance can be used for further differentiation of the students and also expresses the pace of cognition. Students H243 and H91 achieved the same score, but the specific performance of the former one is better. The two students having gained the highest score (H82 and H263) could just be ranked into the group of those with good specific performance as they used more time for good solutions. 


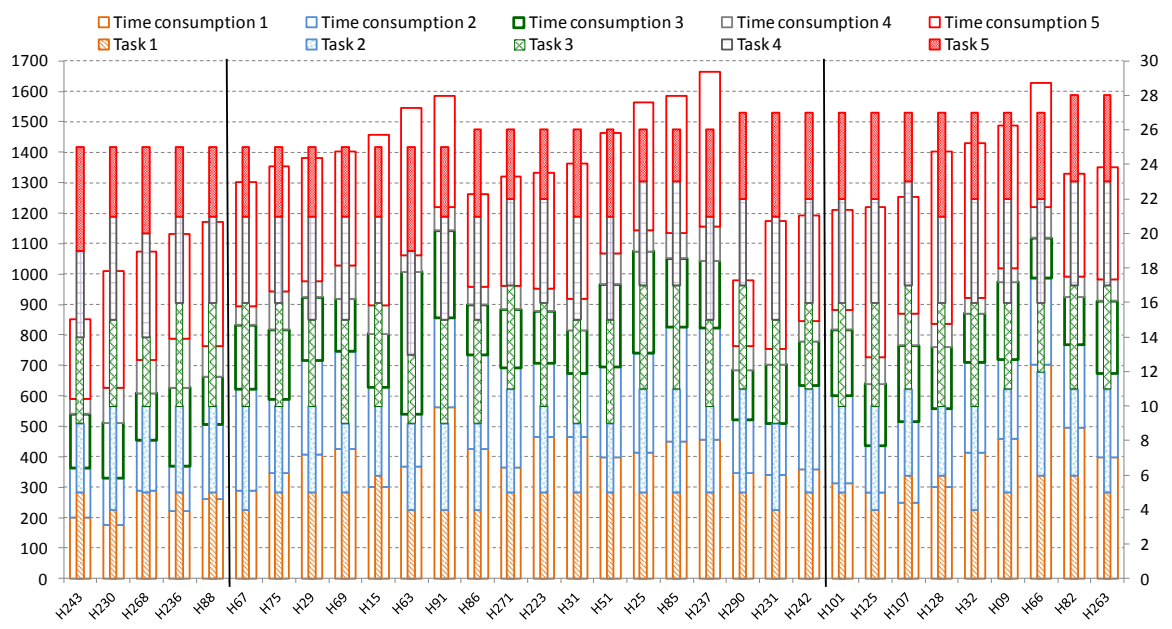

Remark: The left hand vertical axle indicates consumption time while the right hand one shows scores.

Figure 9

Time consumption of the students with highest total scores

We ranked the students according to the achieved scores, as well. The time consumption of the students with high scores appeared within a wide scale, and time consumption increased in parallel with the growth of the score achieved (e.g. the average time of those with 25 points was 1272 , while that of the ones with 26 points was 1444 seconds), i.e. better performance required more time. At the same time, quick-witted students appeared in each score category.

Based on the background variables of the 32 students reaching the best results in the test, the following statements can be made: In the group of the students with the best results, the average of those that:

- Have parents have a degree

- Live in villages

- Live with their parents during their studies

- Took their secondary school leaving exams in four-grade schools

- Study in the IT engineering program

- Gained a mark 5 in Mathematics and Hungarian language and Literature at their school leaving exams was higher.

We also examined the relation between time consumption and achieved points for the whole sample (Figure 10). The relationship can be described in a reasonable way by a power function:

Score $=0.557 *$ Time consumption $^{0.490}$ 
This model accounts for $34.9 \%$ of all of the variances. The ANOVA test indicates a significant regressive relation $(\mathrm{F}=109.348 ; \mathrm{p}<0.05)$. The result of the t-probe of the coefficients of the model shows that time consumption plays an irregularly significant part in the model $(\mathrm{t}=10.480 ; \mathrm{p}<0.05)$.

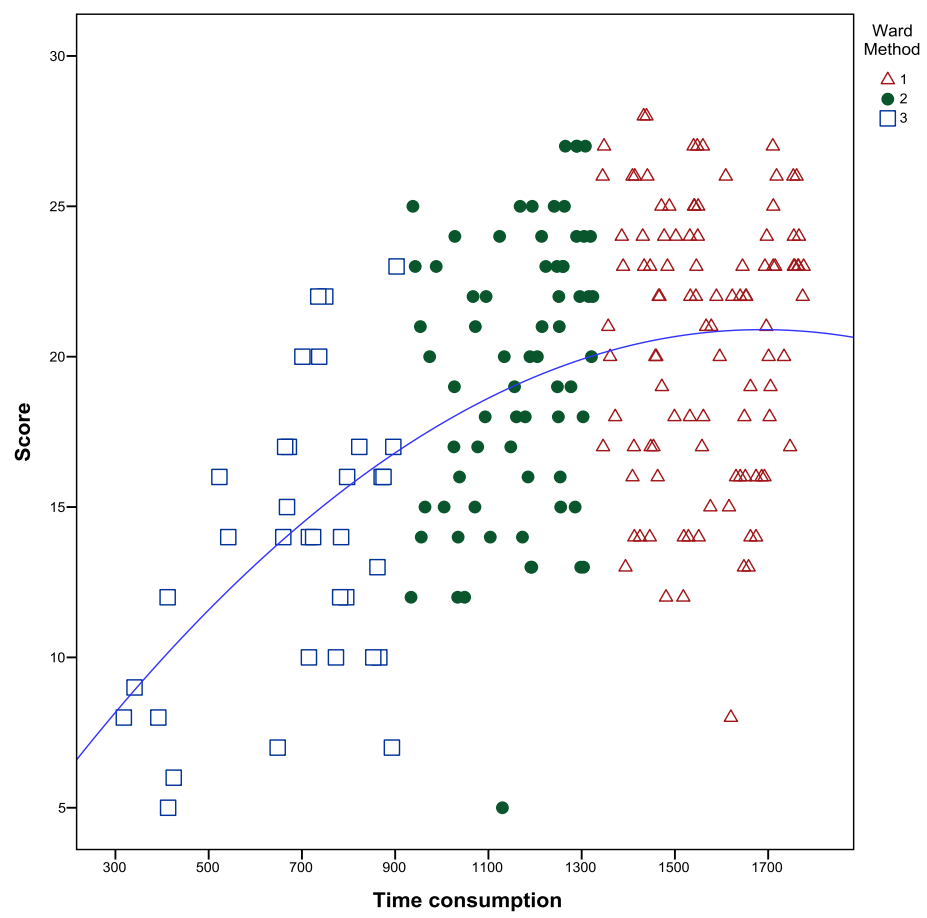

Figure 10

Clusters created in terms of the whole sample and relationship between the time consumption and the total score

In case school leaving exams in Hungarian language and literature and in mathematics are involved as independent variables, the new model will account for $39.1 \%$ of all of the variances $(\mathrm{F}=43.463$; $\mathrm{p}<0.05)$, i.e. they have a relatively low impact. Regarding the coefficients of the linear model and according to the $\mathrm{t}$ probe, both time consumption and the school leaving exam results in the two subjects have a significant weight in the relationship $\left(\mathrm{t}_{\mathrm{time}}=8.414 ; \mathrm{t}_{\text {mathematics }}=\right.$ $5.163 ; \mathrm{t}_{\text {Hungarian }}=-3.101$; for each variable $\left.\mathrm{p}<0.05\right)$ :

Score $=16.367+7 * 10^{-3} *$ Time consumption $-1.954 *$ Maths exam result $1.211 *$ Hungarian exam result

The method of least squares assures that the distribution of the standardized random errors is normal ( $p>0.05$ ), and standard deviation does not depend on the value of the target variable. 
Based on the score achieved in the test and the time needed, we created student groups by cluster analysis (Figure 10), and as it can be seen, the basis of classification was the time needed to solve the tasks. The first group was made of the thorough ones using the whole of the time available $(\triangle)$, the second one involved the considered ones $(\bullet)$, while the third group included the impatient and shallow ones striving to be quick $(\square)$. The clusters were examined according to the cluster centroids (Table 2). The means were analyzed by ANOVA. We found significant differences between the center of certain clusters in terms of both the achieved scores $(\mathrm{F}=34.165 ; \mathrm{p}<0.05)$ and time consumption $(\mathrm{F}=577.226 ; \mathrm{p}<0.05)$. Time spent accounts for $85.0 \%$ of the standard deviation. The reliability of the results was checked by K-means algorithm but no major difference was found.

Table 2

Cluster centroids and standard deviation

\begin{tabular}{|c|c|c|c|}
\hline Cluster & & Score achieved in the test & Time used for task solution \\
\hline \hline \multirow{3}{*}{1} & $\mathrm{M}$ & 20.57 & 1567.50 \\
\cline { 2 - 4 } & $\mathrm{N}$ & 103 & 103 \\
\cline { 2 - 4 } & $\mathrm{SD}$ & 4.491 & 124.255 \\
\hline \multirow{3}{*}{2} & $\mathrm{M}$ & 19.41 & 1165.04 \\
\cline { 2 - 4 } & $\mathrm{N}$ & 68 & 68 \\
\cline { 2 - 4 } & $\mathrm{SD}$ & 4.662 & 118.523 \\
\hline 3 & $\mathrm{M}$ & 13.25 & 660.75 \\
\cline { 2 - 4 } & $\mathrm{N}$ & 36 & 36 \\
\cline { 2 - 4 } & $\mathrm{SD}$ & 4.972 & 212.904 \\
\hline \hline \multirow{3}{*}{ Total } & $\mathrm{M}$ & 18.92 & 1277.60 \\
\cline { 2 - 4 } & $\mathrm{N}$ & 207 & 207 \\
\cline { 2 - 4 } & $\mathrm{SD}$ & 5.306 & 364.164 \\
\hline
\end{tabular}

We examined the composition of the clusters for the whole sample in terms of the background variables, as well, and proved it with the $\chi^{2}$ probe that there was significant correlation between the place of living during the studies $\left(\chi^{2}=32.538\right.$; $\mathrm{p}<0.05)$, the program $\left(\chi^{2}=34.442 ; \mathrm{p}<0.05\right)$, the gender $\left(\chi^{2}=9.366 ; \mathrm{p}<0.05\right)$, the level of language exam $\left(\chi^{2}=14.090 ; \mathrm{p}<0.05\right)$ and belonging to a certain cluster. In terms of these correlations, the contingency coefficient indicating the strength of the relation took these values: $0.369 ; 0.378 ; 0.208 ; 0.252$. These are weakmedium values. The description of the clusters by main and background variables is summarized in Table 3.

The results the students of the five programs achieved in the inductive test taken as a function of the time used for task solution. The "focal points" defined according to the average results of the certain programs are also indicated. C1 mainly consists of students in mechanical engineering and IT engineering, C2 of industrial and product designers, while environmental engineering and land survey and land management engineering students mostly belong to cluster $\mathrm{C} 3$. 
Table 3

Introduction of clusters

\begin{tabular}{|l|c|c|c|}
\hline Cluster & C1 & C2 & C3 \\
\hline \hline Description of cluster & $\begin{array}{c}\text { thorough and } \\
\text { clever }\end{array}$ & considered & $\begin{array}{c}\text { impatient and } \\
\text { shallow }\end{array}$ \\
\hline $\begin{array}{l}\text { Time used for task } \\
\text { solution }\end{array}$ & $1400-1800 \mathrm{sec}$ & $1000-1400 \mathrm{sec}$ & $600-1000 \mathrm{sec}$ \\
\hline Achieved result & $16-26$ points & $15-23$ points & $10-19$ points \\
\hline Sex & male and female & female and male & male \\
\hline Program & $\begin{array}{c}\text { technological } \\
\text { programs }\end{array}$ & designer programs & $\begin{array}{c}\text { environment } \\
\text { related } \\
\text { programs }\end{array}$ \\
\hline Residence during studies & with parents & in sublet or hostel & in hostel \\
\hline Language exam & $\begin{array}{c}\text { medium and/or } \\
\text { advanced level }\end{array}$ & advanced level & none \\
\hline
\end{tabular}

\section{Conclusions}

Since in mathematical and natural scientific knowledge, inductive cognition plays a decisive role, this research aimed to:

(1) Describe the development level of inductive cognition of first grade students leaving secondary education and entering technical higher education.

(2) Prove or disprove the correlation between the time used for task solution and the result achieved in the inductive test.

The research implemented via an online test involved 253 students. By using the measuring tools [18] developed by the Psychometric Success WikiJob Ltd. (UK, London) we came to the following conclusions, in terms of the research participants.

\subsection{Development Level of Students' Inductive Thinking}

The students participating in the survey reached very much differing results in the five tasks. They performed the best in Task3 requiring analogue thinking and the weakest in Task5 containing known operation and requiring diagrammatic reasoning with high standard deviation values in terms of the latter. Difficulties here were probably caused by sensual - perceptual shifts.

We found significant differences in the average results of the certain tasks in line with the results of the school leaving exam in mathematics, i.e. the better result someone had achieved in mathematics, the better result could be expected in the 
test. This concludes that the result of the secondary school leaving exam, in mathematics, closely reflects inductive cognition.

In the two task series requiring diagrammatic reasoning (Task4 and Task5), as well as the series requiring rule induction it was male students living with their parents during their studies and mechanical engineer, electric engineer and engineering IT students who achieved significantly better results.

\subsection{Relationship between the Results Achieved in the Inductive Test and Time Consumption}

Online measurement allowed the registration of time consumption by items, so it was possible to analyze and compare them to the achieved results.

We found close relationship in terms of the time spent on solving the certain tasks - each task consisted of six items - and the average results. Students spent the most time and, with high standard deviation (considerable personal differences), reached the weakest results in the tasks requiring rule induction (Task1) and developed diagrammatic cognition (Task4 and Task5). These phenomena may have several reasons and can be observed well by the applied time analysis by items. In the first case, the standard deviation of time consumption indicates the difficulty level of the given item, while it reflects the problems of understanding the task, as well as, the novel and unusual nature in the latter.

By taking into account the score achieved in the test and the time used for solution, three clusters were created:

(1) The thorough ones utilizing the available time

(2) The considered ones

(3) The impatient and shallow ones striving to be quick

The significant differences of these groups were proved by hierarchic and the Kmeans algorithm, as well. Regarding the composition of the certain groups and in terms of the whole sample, we found that there was significant relationship between the place of residence during the studies, the program, the gender and the level of language exam and belonging to the given cluster.

To describe success, we introduced the notion of specific performance, which we explained as the time needed to achieve a unit of score. We came to the conclusion that it is suitable, for further differentiation of the students' results and expresses the speed of thinking.

The relationship between the two variables is described by a power function and the model accounts for almost $35 \%$ of all of the variances:

Score $=0.557^{*}$ Time consumption ${ }^{0.490}$ 
We made an independent analysis of the results of the students with developed inductive cognition (upper 10\%). In this case, the three clusters gave this picture:

(1) Slow clever ones

(2) Considered to be clever ones

(3) Quick-witted ones

The characteristics of the latter group: their parents have a degree, they are living at their parents' during their studies, they took their secondary school leaving exams at four-grade schools, most of them are studying IT engineering and had marks 5 in mathematics and Hungarian language and literature at their school leaving exams.

The biggest challenge for engineering students is meeting the implications of math and science subjects. Secondary school mathematics graduation results only partially, unless it is an advanced level exam, reliably predict the development of logical thinking. Based on all this, it can be seen that at the beginning of higher education there is a need for an input competence measurement that establishes the development of logical thinking. These measurements can be linked to specific subjects or examine general abilities. In the first case, it could be a special math test, and in the second case, it would be a test measuring inductive thinking. The present research has chosen the latter path. Input competence measurement can provide a good basis for differentiated student development, exploration of learning difficulties, and talent development. Students who perform poorly in input measurement may be offered an optional course specifically designed to develop thinking, while students who achieve good results may be involved in Scientific Students' Associations (Tudományos Diákkör, TDK in Hungarian).

It is important to determine how effectively such an input competency measurement predicts drop-out. To prove this, the results measured in the inductive test must be compared with the students' recorded study results and study progress. This will be the goal of future research.

It is also important to talk about how closely the results obtained in the inductive test, agree with the time spent on the solution. Spending time indicates, on the one hand, the speed of thinking and, on the other hand, perseverance, diligence, patience, concentration, persistence of attention, that is, many attitudes that also play an important role in technical higher education studies.

\section{Acknowledgements}

This research has been supported by the project titled "VEGA-1/0663/19 Analysis of science and mathematics education in secondary schools and innovation of teaching methodology". 


\section{References}

[1] European Commission/EACEA/Eurydice: The European Higher Education Area in 2018: Bologna Process Implementation Report. Luxembourg, Publications Office of the European Union, 2018

[2] Felsőoktatási elemzési jelentések (Analytical reports on higher education): Vol. 2, No. 3, September 2018

[3] Spady, W. G.: Dropouts from higher education: An interdisciplinary review and synthesis. Interchange, 1(1), 1970, pp. 109-121

[4] Bean, J. P.: Interaction effects based on class level in an explanatory model of college student dropout syndrome. American Educational Research Journal, Vol. 22, No. 2, 1985, pp. 35-64

[5] Kocsics, Zs., Pusztai, G.: Student Employment as a Possible Factor of Dropout. Acta Polytechnica Hungarica, Vol. 17, No. 4, 2020, pp. 183-199

[6] Engler, Á.: Non-traditional students in higher education. Hungarian Educational Research Journal, Vol. 9, No. 3, 2019, pp. 560-564

[7] Veroszta, Zs., Nyüsti, Sz.: Institutional effects on Bachelor-Master-level transition. International Journal of Social Sciences, Vol. 4, No. 1, 2015, pp. $39-61$

[8] Kautz, T. D., Heckman, J., Diris, R., der Weel, B., Borghans, L.: Fostering and measuring skills: Improving cognitive and non-cognitive skills to promote lifetime success. National Bureau of Economic Research, Cambridge, 2014

[9] Balcar, J.: Soft skills and their wage returns: Overview of empirical literature. Review of Economic Perspectives, Vol. 14, No. 1, 2014, pp. 3-15

[10] Carnevale, A. P.: $21^{\text {st }}$ Century competencies for college and career readiness. National Career Development Association, Broken Arrow, 2013

[11] Eger, H., Grossmann, V.: Noncognitive abilities and within-group wage inequality. Institute for the Study of Labour, Bonn, 2004

[12] Manpower Group: Talent Shortage Survey Research Results. Manpower Group, Milwaukee, 2015

[13] Klauer, K. J., Phye, G. D.: Inductive Reasoning: A Training Approach. Review of Educational Research, Vol. 78, No. 1, 2008, pp. 85-123

[14] Phye, G. D.: Inductive problem solving: Schema inducement and memorybased transfer. Journal of Educational psychology, Vol. 82, No. 4, 1990, pp. 826-831

[15] Mackintosh, N. J.: IQ and human intelligence. Oxford University Press, Oxford, 1998

[16] Sternberg, R. J., Ben-Zeev, T. (Eds.): The nature of mathematical thinking. Lawrence Erlbaum, Mahwah, 1996 
[17] Winch, C.: Language, ability and educational achievement. Routledge, New York, 1990

[18] Newton, P., Bristoll, H.: Numerical reasoning, verbal reasoning, abstract reasoning, personality tests. Psychometric Success. https://www.psychometric-success.com/ Accessed on March 2019

[19] Georgiev, N.: Item Analysis of C, D and E Series from Raven's Standard Progressive Matrices with Item Response Theory Two-Parameter Logistic Model. Europe's Journal of Psychology, Vol. 4, No. 3, 2008, https://doi.org/10.5964/ejop.v4i3.431

[20] Raven, J.: The Raven's Progressive Matrices: Change and Stability over Culture and Time. Cognitive Psychology, Vol. 41, No. 1, 2000, pp. 1-48

[21] Jacobs, P. I., Vandeventer, M.: Progressive Matrices: An experimental, developmental, nonfactorial analysis. Perceptual and Motor Skills, Vol. 27, No. 3, 1968, pp. 759-766

[22] Vodegel Matzen, L. B. L., Van der Molen, M. W., Dudink, A. C. M.: Error analysis of Raven test performance. Personality and Individual Differences, Vol. 16, No. 3, 1994, pp. 433-445

[23] Sternberg, R. J.: Component processes in analogical reasoning. Psychological Review, Vol. 84, No. 4, 1977, pp. 353-378

[24] Stieff, M., Hegarty, M., Dixon, B.: Alternative strategies for spatial reasoning with diagrams. In: Goel, A., Jamnik, M., Narayanan, N. H. (Eds.): Diagrammatic Representation and Inference. Springer, Berlin, Heidelberg, 2010, pp. 115-127

[25] Eger, L., Klement, M., Tomczyk, Ł, Pisoňová, M., Petrová, G.: Different User Groups of University Students and their ICT Competence: Evidence from three Countries in Central Europe. Journal of Baltic Science Education. Vol. 17, No. 5, 2018, pp. 851-866

[26] Szököl, I., Nagy, M.: The Qualitative Transformation of Understanding the Essence of the Education Process and Learning. In: Chova, L. G., Martínez, A. L. (eds.): Proceedings of $12^{\text {th }}$ Annual International Conference on Education and New Learning Technologies, Palma de Mallorca, 2020, http://doi.org/10.21125/edulearn.2020

[27] Harangus, K.: Examining the relationships between problem-solving and reading comprehension skills. New Trends and Issues Proceedings on Humanities and Social Sciences. Vol. 6, No. 5, pp. 66-74, https://doi.org/10.18844/prosoc.v6i5.4375

[28] Csehi, A., Kanczné Nagy, K., Tóth-Bakos, A.: Experience education to alleviate fears of educator candidates in their university studies. AD ALTA: Journal of Interdisciplinary Research, Vol. 10, No. 2, 2020, pp. 170-175, www.doi.org/10.33543/1002 